\title{
HISTORIA DE LA CIRURGIA VASCULAR
}

\section{HISTORY OF THE VASCULAR SURGERY} en cuevas, teniendo que cazar para comer y estar siempre cambiando de sitio para escapar del frío o de un enemigo. ¿Es posible que este hombre presentase alguna enfermedad vascular? - probablemente no. La intensa actividad física, la alimentación pobre en grasas y la corta longevidad hacen que se aleje de esta posibilidad. ¿Entonces de donde surgieron las enfermedades vasculares y cómo surgió la preocupación del hombre en tratarlas? La mayoría de las enfermedades venosas se relacionan con la propia evolución física del hombre, que ha dejado los animales cuadrúpedos para atrás y ha evolucionado para caminar en posición ortostática, en cuanto que las enfermedades arteriales (arteriosclerosis) se relacionan principalmente con la alimentación, el tabaco y el gran aumento de la longevidad.

Te invitamos a un viaje por la historia de la cirugía vascular y nuestra primera parada es en el antiguo Egipto. Ya en aquella época los hombres no escapaban a las enfermedades vasculares y en el famoso papiro de Evers, datado de $1550 \mathrm{aC}$, vemos a los antiguos egipcios tratando varices, úlceras venosas y hemorroides mediante su cauterización. En la Biblia, el rey Ezequiel es curado de una úlcera venosa crónica por Isaías. Posteriormente en la antigua Grecia, Hipócrates recomendaba tratar las varices mediante múltiples punciones con el objetivo de trombosarlas. Algunos siglos después, Galeno practicaba la incisión quirúrgica de las varices con posterior cauterización, para provocar su destrucción.

Ahora ya estamos en la alta edad media, en esa época la medicina árabe se encontraba muy desarrollada y es a los árabes a quien debemos el nombre de la vena safena, que significa oculta - "Al-safen". Ya en la edad moderna, muchos nombres se destacan en la historia de la medicina vascular. Padua descubre las válvulas venosas. En el siglo XVII, Harvey profesor de Anatomía de la Universidad de Londres descubre la circulación sanguínea tal y como la conocemos hoy.

Edad contemporánea a la vista. El desarrollo de la medicina se acelera y la angiología se perfecciona. En 1888, Matas realiza una ligadura proximal y distal de un aneurisma traumático de la arteria braquial, siendo el primer autor de escribir la técnica de "endoaneurismorrafia". Más fue en 1902, que Alexis Carrel publicó una nueva técnica de sutura vascular para la realización de anastomosis, Siendo un marco en el desarrollo de la cirugía vascular moderna. Los actuales principios y técnicas utilizadas se fundamentan en sus estudios, habiendo sido ganador del premio Nobel.
Imagínate un hombre nómada primitivo y viviendo Fabricio D'Acquapendente, profesor de la Universidad de

\author{
TCBC-RJ - Gaudencio Espinosa \\ Director del Departamento Vascular \\ Jefe del Servicio de Angiología y Cirugía Vascular \\ Clínica Universitaria de Navarra \\ Universidad de Navarra - España
}

No fueron solamente grandes nombres que llevaron al desarrollo de la especialidad. Hechos históricos también contribuyeron para su crecimiento. Fue durante la guerra de Corea, por ejemplo que ocurrió uno de los mayores avances del conocimiento para el tratamiento de las lesiones traumáticas vasculares. En los campos de batalla, la medicina vascular tuvo héroes que curaban y otros que eran curados.

Las primeras arteriografías y venografías realizadas en el ser humano datan de la década 20, cuando Berberich e Hiersch, en 1923 y Brooks 1924 utilizaron respectivamente brometo de estroncio y yodeto de sodio en sus estudios angiográficos. Todavía en esa misma época fueron obtenidos dos grandes avances en el estudio angiográfico de las enfermedades vasculares. El primero fue 1928 cuando Egaz Moniz, en Lisboa, describe la técnica de arteriografía cerebral mediante punción directa de la arteria carótida y el segundo ocurrió inmediatamente después cuando Reynaldo dos Santos en 1929 utilizó la punción translumbar para visualizar la aorta abdominal. Posteriormente, en 1946, Cid dos Santos realizó con éxito la primera endarterectomía para restablecimiento del flujo arterial utilizando la anticoagulación sistémica con heparina. La primera resección de un aneurisma de aorta abdominal fue descrita por Dubost en 1951, un principio que rápidamente fue aplicado en el tratamiento de las enfermedades de la aorta torácica.

Con la evolución de la informática a finales del siglo XX la cirugía vascular sufrió un gran desarrollo de los métodos de imagen. La angiografía por sustracción digital, la Tomografía helicoidal y la resonancia magnética son capaces de ofrecernos imágenes extremamente precisas de la anatomía vascular.

Una nueva era empieza en 1953, cuando Seldinger describe una nueva técnica realizada por vía percutánea. Esta consiste en la punción de un vaso con una aguja a través de la piel, por donde se introduce un cuerda guía, que sirve de sustentación para la introducción de un catéter, permitiendo así el cateterismo selectivo de prácticamente todos los principales territorios vasculares del organismo.

También fue en la segunda mitad del siglo XX que Grünztzig, en 1974, desarrolló un catéter balón utilizado para realizar la angioplastia coronaria. Actualmente los balones pueden ser utilizados en cualquier arteria del organismo humano, siendo inflados bajo control radiológico con la intención de dilatar las lesiones ateroscleróticas. Sin embargo, la consolidación de los procedimientos mínimamente invasivos para tratar las enfermedades vasculares llegó en 1988 con el uso de una prótesis endovascular metálica 
desarrollada por el Dr. Julio Palmaz, denominada stent. El inicio de los años 90 constituye un verdadero marco en la evolución de las técnicas mínimamente invasivas y en el origen de la llamada Cirugía Endovascular, cuando el Dr. Juan Parodi, en Buenos Aires, demostró la posibilidad de tratar los aneurismas de aorta evitando la cirugía abierta, mediante el implante de una endoprótesis que se inserta a través de la arteria femoral. Esta endoprótesis es liberada en la aorta y se expande hasta adherir a la pared arterial, sin necesidad de suturas.
Nuestro viaje llega finalmente al siglo XXI. Lo que algunos consideraron inicialmente tratamientos experimentales, se han convertido en técnicas quirúrgicas frente a la cirugía abierta, para muchas enfermedades vasculares. En concreto, se calcula que un futuro cercano el tratamiento de más de un $70 \%$ de las enfermedades vasculares más importantes será practicado mediante técnicas mínimamente invasivas endovasculares. El futuro todavía no ha llegado, más después de este viaje es fácil imaginar que impresionante será. 